\title{
The role of concomitant methotrexate dosage and maintenance over time in the therapy of rheumatoid arthritis patients treated with adalimumab or etanercept: retrospective analysis of a local registry
}

This article was published in the following Dove Press journal: Drug Design, Development and Therapy

\author{
Ennio Giulio Favalli' \\ Andrea Becciolini' \\ Martina Biggioggero 2 \\ Ilaria Bertoldi ${ }^{3}$ \\ Chiara Crotti ${ }^{2}$ \\ Maria Gabriella Raimondo 2 \\ Antonio Marchesoni' \\ 'Department of Rheumatology, \\ Gaetano Pini Institute, Milan, Italy; \\ ${ }^{2}$ Department of Clinical Sciences \\ and Health Community, University \\ of Milan, Division of Rheumatology, \\ Gaetano Pini Institute, Milan, Italy; \\ ${ }^{3}$ Pfizer Innovative Health, I\&I Medical \\ Affairs, Rome, Italy
}

Objective: To evaluate the pattern of prescription and maintenance over time of concomitant methotrexate (MTX), and its impact on a 2-year clinical response in a cohort of rheumatoid arthritis (RA) patients treated with a first-line tumor necrosis factor alpha inhibitor (TNFi).

Patients and methods: The study population included all RA patients receiving adalimumab or etanercept a as first-line biologic drug, extracted from a local registry. Enrolled patients were stratified into 3 subgroups according to baseline concomitant MTX: no MTX, low-dose MTX ( $\leq 10 \mathrm{mg} / \mathrm{wk}$ ), and high-dose MTX ( $\geq 12.5 \mathrm{mg} / \mathrm{wk})$. The 2-year persistence of the initial MTX regimen was computed by the Kaplan-Meier method, and a Cox proportional hazard model was developed to examine potential predictors of MTX withdrawal/change of dosage. European League Against Rheumatism remission and good-to-moderate response were evaluated according to baseline MTX regimen and MTX maintenance over time.

Results: A total of 330 patients (163 treated with adalimumab and 167 with etanercept) were included; 141 were prescribed TNFi without MTX and 112 received low-dose and 77 high-dose concomitant MTX. Male sex, younger age, and shorter mean disease duration were predictors of high-dose MTX use. Among MTX users (76.2\% parenteral and 23.8\% oral), initial MTX dose persisted over time in $79.9 \%$ at 1 year and $70.2 \%$ at 2 years. Fifty-one patients $(27 \%)$ underwent MTX dose de-escalation/discontinuation because of intolerance/adverse events. The 2-year EULAR remission rate was higher in the patients receiving and maintaining high-dose MTX than in those receiving low-dose or no MTX (46.2\% vs $29.5 \%$ and $23.4 \%$, respectively; $p=0.009)$. The same was true for good-to-moderate response rate $(71.2 \%$ vs $52.6 \%$ and $50.4 \%$, respectively; $p=0.031$ ).

Conclusion: In a real-life setting, about one-third of RA patients treated with TNFis experienced dose reduction/discontinuation of concomitant MTX because of intolerance/adverse events over a 2-year follow-up period. Initial high-dose MTX and its maintenance over time are associated with better 2-year clinical response.

Keywords: rheumatoid arthritis, methotrexate, biologic drugs, combination therapy, etanercept, adalimumab

\section{Introduction}

In the past 20 years, the treatment and the expected outcome of rheumatoid arthritis (RA) have been dramatically improved by the application of novel strategies for the 
management of the disease, including the early introduction of disease-modifying anti-rheumatic drugs (DMARDs) and a treat-to-target approach. ${ }^{1}$ To date, methotrexate (MTX) is still renowned as the anchor drug for initial treatment of early RA, and the combination of MTX with a biologic agent (bDMARD) is considered as the standard of care for treating RA refractory to conventional synthetic DMARDs (csDMARDs) alone. ${ }^{2}$ This approach is mainly the result of the earliest Phase III studies conducted with tumor necrosis factor alpha inhibitors (TNFis), which demonstrated that the clinical response to bDMARDs is significantly improved by the addition of a csDMARD, primarily MTX. ${ }^{3-8}$ Subsequently, these findings have been confirmed by real-life experience with TNF blockers ${ }^{9-12}$ and extended to other bDMARDs with different mechanisms of action, such as costimulation blockade or B-cell depletion. ${ }^{13,14}$ As a consequence of this clinical experience, four of the bDMARDs available for the treatment of RA (infliximab, golimumab, abatacept, and rituximab) require concomitant therapy with MTX according to the product label. Moreover, international recommendations for the management of RA suggest that, in the absence of clear contraindications, all bDMARDs should be commenced in combination with MTX. ${ }^{15,16}$ However, data coming from observational bDMARD registries have surprisingly disclosed that more than one-third of patients receive TNFi monotherapy in daily practice. Possible explanations for failure to use concomitant MTX are that patients have specific contraindications, experience minor but bothersome side effects, or do not comply with prescribed treatment. ${ }^{11,17-22}$

Furthermore, the optimal MTX regimen to be used in combination with bDMARDs still remains unclear, ranging from 7.5 to $25 \mathrm{mg} / \mathrm{wk}$ according to national guidelines and physician's preference. Recently, the CONCERTO trial demonstrated a robust and dose-dependent clinical response with ascending doses of MTX in a cohort of early RA patients treated with adalimumab (ADA), showing significantly higher efficacy with at least $10 \mathrm{mg} /$ wk MTX. ${ }^{23}$ On the other hand, a post hoc analysis of the TEMPO and COMET trials showed that the efficacy of etanercept (ETA) is not dependent on concomitant MTX dosage, ${ }^{24}$ similar to what was reported by a retrospective analysis of the DREAM registry conducted on all TNFis. ${ }^{25}$ Nevertheless, data on the actual role of different MTX regimens in clinical practice are still lacking.

Moreover, the vast majority of observational studies addressing the role of MTX in combination with bDMARD classified monotherapy and combination therapy according to the baseline reported use of MTX, irrespective of MTX maintenance over time. However, MTX is frequently described as a generally poorly tolerated drug, ${ }^{26}$ and a significant proportion of MTX users are reported to be nonadherent with the prescribed MTX regimen. ${ }^{27,28}$ To date, the pattern and role of concomitant MTX maintenance in TNFi-treated patients have rarely been described in detail.

To fill this gap, we performed a retrospective analysis of a local registry, including ADA- or ETA-treated RA patients, with the aim of evaluating the prevalence and dosage regimen of baseline concomitant MTX, the reasons for TNFi monotherapy, and the baseline predictive factors of MTX use and dosage in a real-life setting. Moreover, we analyzed the 2-year retention rate of MTX and the frequency of MTX dose decreases in combination with TNFis for the first time, evaluating the effect of MTX regimen changes or discontinuation on the clinical response to ADA and ETA over time.

\section{Patients and methods Study population}

Data from all RA patients aged $\geq 18$ years fulfilling the American College of Rheumatology 1987 revised criteria, ${ }^{29}$ treated with bDMARDs between January 2001 and December 2013 in our Rheumatology Unit, were analyzed. The eligible study population was extracted from a local registry approved by the Gaetano Pini Institute Ethics Committee and included all patients who signed the informed consent form for any subsequent retrospective analysis of their clinical data. All analyzed clinical information was reported as anonymous aggregate data and excluded any identifiable medical information. For all patients, the database includes data on demographic features (age, sex, and time since RA diagnosis); clinical parameters (C-reactive protein, erythrocyte sedimentation rate level, rheumatoid factor (RF) positivity, disease activity score 28-ESR [DAS28], and Health Assessment Questionnaire [HAQ] score); and therapeutic data (biologic therapy and concomitant MTX). All the disease and treatment follow-up data were collected at baseline and then every 6 months until December, 2014, with the sole exception of data regarding concomitant MTX, which were collected every 2 months. The final analysis was conducted including only patients who had received as first-line bDMARD ADA or ETA, which can be prescribed as monotherapy according to their product label. Exclusion criteria were previous therapy with a different bDMARD and the enrollment in a randomized controlled trial. Treatments were administered as part of routine care in accordance with RA good clinical practice; TNFis were prescribed according to their licensed regimen, and concomitant csDMARDs or 
corticosteroids were administered if ordered by the referring rheumatologist. The study population was stratified into 3 subgroups according to baseline concomitant MTX therapy (no MTX, low-dose MTX [7.5-10 mg/wk], and high-dose $\operatorname{MTX}[\geq 12.5 \mathrm{mg} / \mathrm{wk}])$. The combination with concomitant csDMARD other than MTX was considered according to that reported by international recommendations, suggesting a definite role as csDMARD in the management of RA only for sulfasalazine and leflunomide. Thus, patients treated with concomitant hydroxychloroquine or cyclosporine were included in the "no MTX" subgroup, whereas patients receiving concomitant leflunomide or sulfasalazine were excluded from the study population before the final analysis. Changes in MTX regimen over time in each subgroup were recorded every 2 months, and reasons for dose decrease or withdrawal were evaluated.

\section{Outcomes and statistical analysis}

Descriptive statistics were used to calculate mean and SD, and median and interquartile range (IQR). Differences between treatment subgroups were analyzed by the Kruskal-Wallis nonparametric test for continuous variables and $\chi^{2}$ test for categorical variables.

The 2-year retention rate of each concomitant MTX regimen was computed by the Kaplan-Meier method and compared by a stratified log-rank test. Univariate and multivariate Cox proportional hazard models were developed to examine potential predictors of MTX withdrawal/change of dosage. Results are presented as hazard ratios (HRs) with 95\% confidence intervals (95\% CIs).

Clinical response was evaluated as 6-, 12-, and 24-month DAS28 mean changes from baseline, proportion of patients achieving DAS28 remission or LDA, and proportion of patients achieving good/moderate EULAR response. In order to quantify the impact of MTX concomitant treatment on long-term clinical response, these outcomes were compared in the 3 subgroups according to the maintenance over time of baseline MTX dosage, excluding the patients who discontinued/reduced MTX because of a stable clinical remission. Moreover, the 2-year TNFi retention rate was calculated by the Kaplan-Meier method, and the difference in the 3 subgroups according to concomitant MTX regimen was computed by a stratified log-rank test.

Comparative analyses of baseline characteristics in the 3 subgroups of MTX treatment were computed by using the Kruskal-Wallis $t$-test and the $\chi^{2}$ test for continuous and dichotomous variables, respectively. Statistical analyses were performed using SPSS statistical software, version 20.0 (IBM Corporation, Armonk, NY, USA). $p$-Values $\leq 0.05$ were considered statistically significant.

\section{Results}

\section{Study population}

A total of 330 patients (163 treated with ADA and 167 with ETA) were included in the study (patient disposition is reported in Figure 1). The baseline demographic and clinical

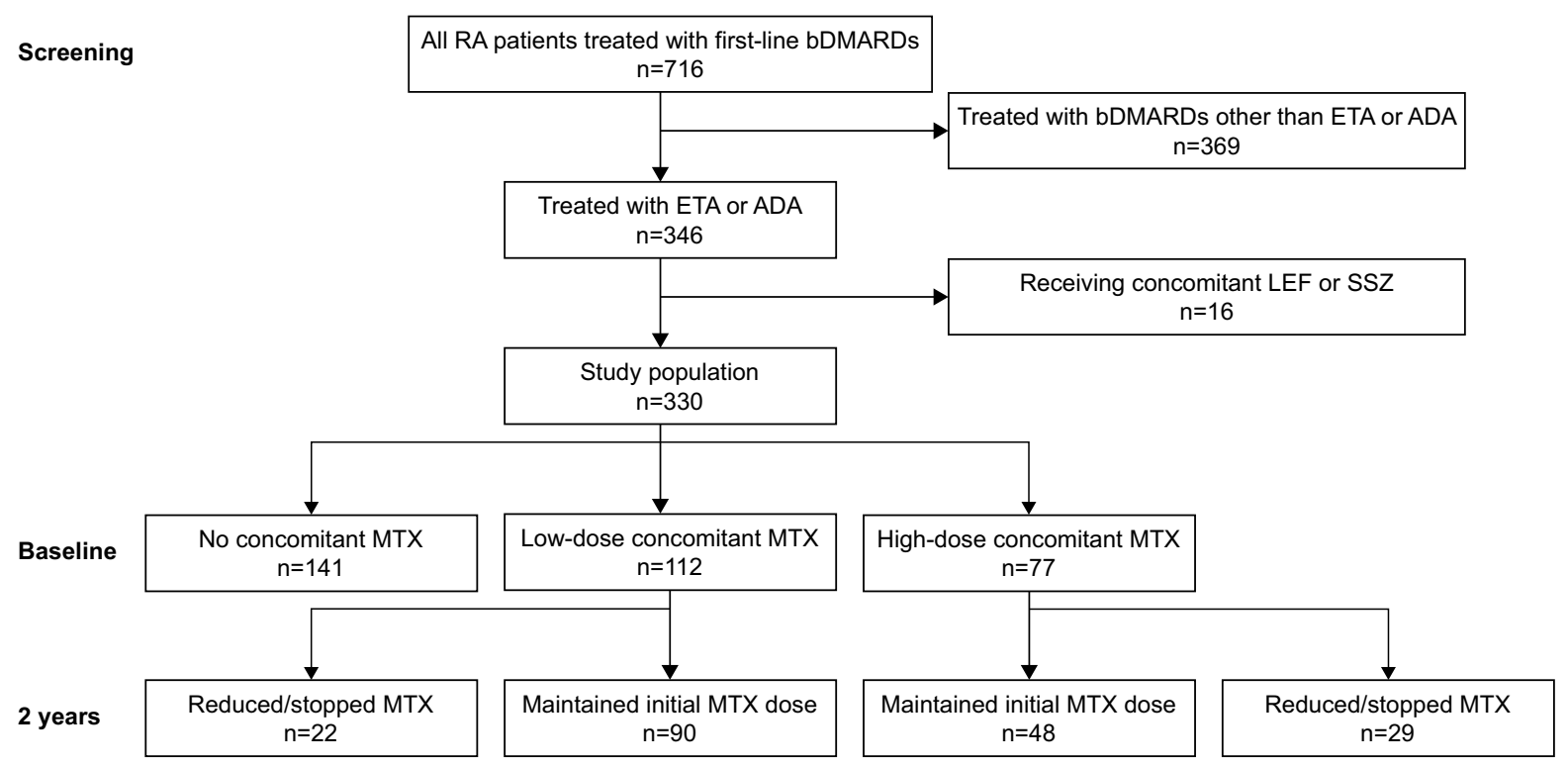

Figure I Disposition of patients during the 2-year follow-up period.

Abbreviations: RA, rheumatoid arthritis; bDMARDs, biologic Disease Anti-Rheumatic Drugs; ETA, etanercept; ADA, adalimumab; LEF, leflunomide; SSZ, sulfasalazine; MTX, methotrexate. 
Table I Baseline characteristics of study population

\begin{tabular}{|c|c|c|c|c|}
\hline \multirow[t]{3}{*}{ Baseline characteristics } & \multicolumn{3}{|c|}{ Concomitant MTX } & \multirow[t]{3}{*}{$p$-value* } \\
\hline & No MTX & Low-dose & High-dose & \\
\hline & $n=|4|$ & MTX $n=1 / 2$ & MTX n=77 & \\
\hline Age, mean \pm SD (years) & $53.7 \pm \mid 3.1$ & $56.2 \pm 12.9$ & $49.4 \pm 12.2$ & 0.001 \\
\hline Female (\%) & 117 (82.9\%) & 98 (87.5\%) & $56(72.7 \%)$ & 0.037 \\
\hline Disease duration, mean \pm SD (years) & $12.6 \pm 9.2$ & $12.7 \pm 9.7$ & $8 \pm 7.1$ & $<0.001$ \\
\hline DAS28, mean \pm SD & $5.20 \pm 1.3 \mid$ & $5.27 \pm 1.19$ & $5.44 \pm 1.12$ & 0.521 \\
\hline HAQ-DI, mean \pm SD & $1.39 \pm 0.6 \mathrm{I}$ & $1.36 \pm 0.52$ & $1.44 \pm 0.54$ & 0.644 \\
\hline RF positive, n (\%) & 112 (79.4\%) & 85 (75.9\%) & 55 (7I.4\%) & 0.636 \\
\hline $\mathrm{TNFi}$ & & & & 0.065 \\
\hline ETA & 71 & 49 & 47 & \\
\hline ADA & 70 & 63 & 30 & \\
\hline
\end{tabular}

Notes: *Comparative analyses were computed by using the Kruskal-Wallis $t$-test and the $\chi^{2}$ test for continuous and dichotomous variables, respectively. Abbreviations: MTX, methotrexate; SD, standard deviation; DAS28, Disease Activity Score 28; HAQ-DI, Health Assessment Questionnaire Disability Index; RF, rheumatoid factor; TNFi, tumor necrosis factor inhibitor; ETA, etanercept; ADA, adalimimab.

characteristics are listed in Table 1. Briefly, 271 (82.1\%) were female, mean ( \pm standard deviation) age was $53.6 \pm 13.1$ years, mean disease duration 11.6 \pm 9.2 years, mean DAS28 $5.28 \pm 1.21$, mean HAQ $1.39 \pm 0.56$, and RF positivity $76.4 \%$. Among 141 (42.7\% of whole population) patients not receiving concomitant treatment with MTX at baseline (70 patients in the ADA group and 71 in the ETA one), 36 were concomitantly treated with hydroxychloroquine, 4 with cyclosporine, and 101 received the TNFi as pure monotherapy. Reasons for failure to use MTX in the latter group were reported as subjective intolerance $(n=63)$, hepatotoxicity $(n=20)$, and poor compliance $(\mathrm{n}=18)$. MTX was administered parenterally to $76.2 \%$ and orally to $23.8 \%$ of patients at a median dose of $10 \mathrm{mg} / \mathrm{wk}$ (IQR 7.5-12.5 mg/wk). About 112 (33.9\%) patients received concomitant low-dose MTX $(\leq 10 \mathrm{mg} / \mathrm{wk})$ and 77 (23.4\%) high-dose MTX ( $\geq 12.5 \mathrm{mg} / \mathrm{wk})$. Compared with no MTX and low-dose MTX, high-dose MTX group was associated with male sex $(17 \%, 12.5 \%$, and $21.3 \%$, respectively; $p=0.032)$, younger age $(53.7,56.2$ and 49.4 years, respectively; $p=0.001$ ), and shorter mean disease duration $(12.6,12.3$ and 8 years, respectively; $p<0.001)$. Conversely, no statistically significant differences in RF positivity, mean baseline DAS28 and HAQ score, and the proportion of patients treated with ETA vs ADA were observed among the 3 subgroups.

\section{Analysis of the retention rate of the MTX baseline regimen}

Among the 189 patients receiving MTX at baseline, 138 maintained a stable MTX dose throughout the entire followup period, whereas 51 (22 in the low-dose and 29 in the high-dose MTX group, respectively) underwent MTX dose de-escalation by a median dose of $7.5 \mathrm{mg}$ (IQR 5-10 mg/wk). Of these 51 patients, 9 ( 5 in the high-dose and 4 in the low-dose MTX group, respectively) remained in the same subgroup of MTX regimen after dose reduction and 24 (17 in the low-dose and 7 in the high-dose MTX group, respectively) stopped MTX. The following reasons for MTX tapering/stopping were recorded: intolerance $(n=28)$, hepatotoxicity $(n=10)$, disease remission $(n=6)$, poor compliance $(n=2)$, alopecia $(n=2)$, thrombocytopenia $(n=1)$, surgery $(n=1)$, and recurrent infections $(n=1)$. Excluding the patients in whom MTX dose was reduced because of clinical remission, the persistence of the baseline MTX regimen was $79.9 \%$ at 1 year and $70.2 \%$ at 2 years (Figure 2 ). The proportion of patients who did not stop MTX was $89.7 \%$ at 1 year and $84.2 \%$ at 2 years. According to the multivariate

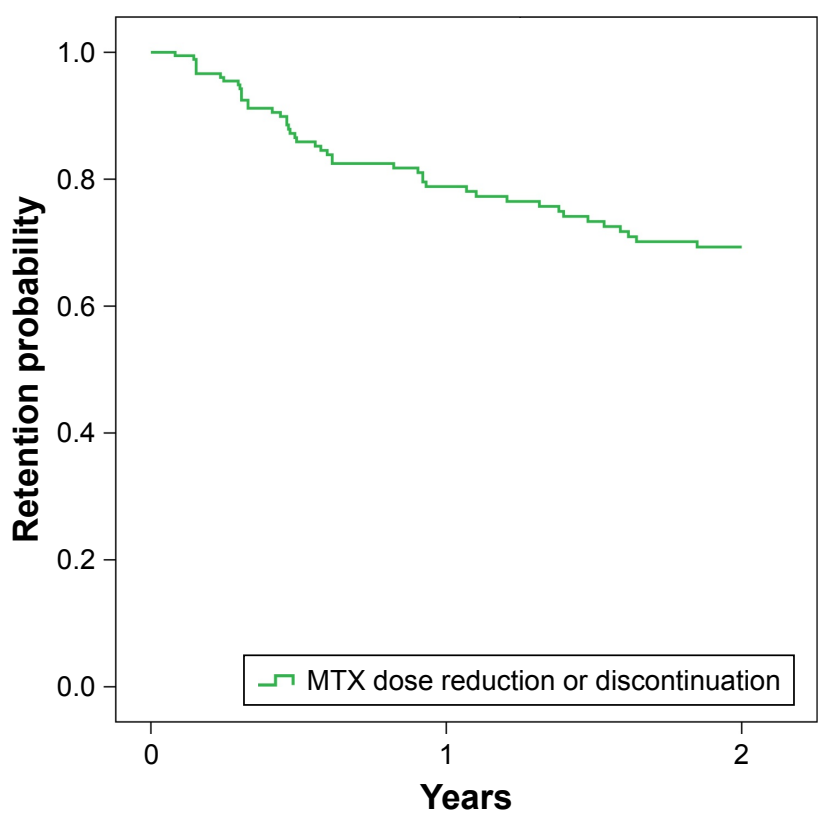

Figure 2 Retention probability of maintaining the baseline concomitant MTX regimen over the first 2 years.

Abbreviation: MTX, methotrexate. 
Table 2 Multivariate logistic regression of baseline predictors of good/moderate EULAR response at 6, 12 , and 24 months

\begin{tabular}{|c|c|c|c|}
\hline \multirow{2}{*}{$\begin{array}{l}\text { Baseline } \\
\text { characteristics }\end{array}$} & \multicolumn{3}{|l|}{ OR (95\% Cl) } \\
\hline & 6 months & 12 months & 24 months \\
\hline Female sex & 0.45 I (0.233-0.869) & $0.465(0.239-0.904)$ & $0.505(0.262-0.973)$ \\
\hline Age & $0.982(0.962-1.002)$ & $0.991(0.97 I-1.011)$ & $0.989(0.970-1.009)$ \\
\hline Disease duration & $1.005(0.978-\mid .031)$ & $0.993(0.967-1.020)$ & $1.000(0.974-1.026)$ \\
\hline RF & I.70I (0.950-3.046) & $1.669(0.930-2.995)$ & $1.280(0.722-2.267)$ \\
\hline DAS28 & I.577 (I.2। I8-2.042) & $1.419(1.100-1.831)$ & $1.439(1.116-1.854)$ \\
\hline HAQ-DI & $0.856(0.498-1.473)$ & $1.130(0.657-1.944)$ & 0.93 I $(0.543-1.596)$ \\
\hline \multicolumn{4}{|l|}{ Concomitant MTX } \\
\hline High-dose & $\mathrm{I} .644$ (I.043-2.589) & $2.358(1.468-3.789)$ & $2.140(1.344-3.406)$ \\
\hline Low-dose & $1.190(0.785-1.803)$ & I.238 (0.8II-I.887) & I.I87 (0.78I-I.804) \\
\hline No MTX & 1 & I & 1 \\
\hline
\end{tabular}

Abbreviations: OR, odds ratio; 95\% Cl, 95\% confidence interval; RF, rheumatoid factor; DAS28, Disease Activity Score 28; HAQ-DI, Health Assessment Questionnaire Disability Index; MTX, methotrexate.

Cox model, longer disease duration at baseline was associated with a higher probability of retaining MTX initial dosage (HR $=0.951,95 \%$ CI: $0.915-0.989 ; p=0.012)$, whereas RF positivity ( $\mathrm{HR}=1.691,95 \% \mathrm{CI}: 0.928-3.081 ; p=0.086)$, mean DAS28 (HR $=0.802,95 \%$ CI: $0.582-1.106 ; p=0.179)$, mean HAQ score (HR $=0.973,95 \%$ CI: $0.468-2.022 ; p=0.941$ ), $\operatorname{sex}(\mathrm{HR}=0.615,95 \%$ CI: $0.332-1.139 ; p=0.122)$, and age (HR $=1.006,95 \%$ CI: $0.983-1.031 ; p=0.606)$ were not predictors of MTX regimen persistence.

\section{Baseline predictors of good $/$ moderate EULAR response}

The baseline predictors of 6-, 12-, and 24-month good/ moderate EULAR response, evaluated by a logistic regression model, are reported in Table 2. Briefly, at all the 3 time points, MTX high-dose regimen $(>12.5 \mathrm{mg} / \mathrm{wk})$ and high baseline DAS28 were associated with high probability of achieving good/moderate EULAR response, whereas female sex was associated with low probability. Age and disease duration at the moment of bDMARD introduction, as well as RF positivity and baseline HAQ score, were not predictors of clinical response.

\section{Effectiveness and retention rate analysis of TNFis according to maintenance over time of baseline MTX regimen}

In order to evaluate the possible impact of concomitant hydroxychloroquine or cyclosporine on TNFi performance, we first compared the subgroup treated with pure TNFi monotherapy and patients concomitantly receiving the previously mentioned two csDMARDs, finding no difference in both 2-year TNFi persistence $(48.7 \%$ and $50 \%$, respectively; $p=0.835)$ and DAS28 remission rate $(23.4 \%$ and $28.3 \%$, respectively; $p=0.125$ ). Thus, as described in the
"Patients and methods" section, subsequent analyses were performed including in the "TNFi without MTX" subgroup both the patients treated with hydroxychloroquine or cyclosporine and the ones receiving TNFi pure monotherapy.

The 2-year retention rate of first-line TNFi was higher, although not statistically significant, in the stable highdose MTX-treated group than in both the low-dose and no MTX groups (68.8\%, 56.8\%, and $49.1 \%$, respectively; $p=0.112$ ) (Figure 3). Similar results were observed after the stratification of TNFi withdrawals according to reason for discontinuation (inefficacy $[80.7 \%, 73.8 \%$, and $68.6 \%$, respectively; $p=0.344]$ or adverse events [ $85.4 \%, 77.4 \%$, and $72 \%$, respectively; $p=0.322]$ ).

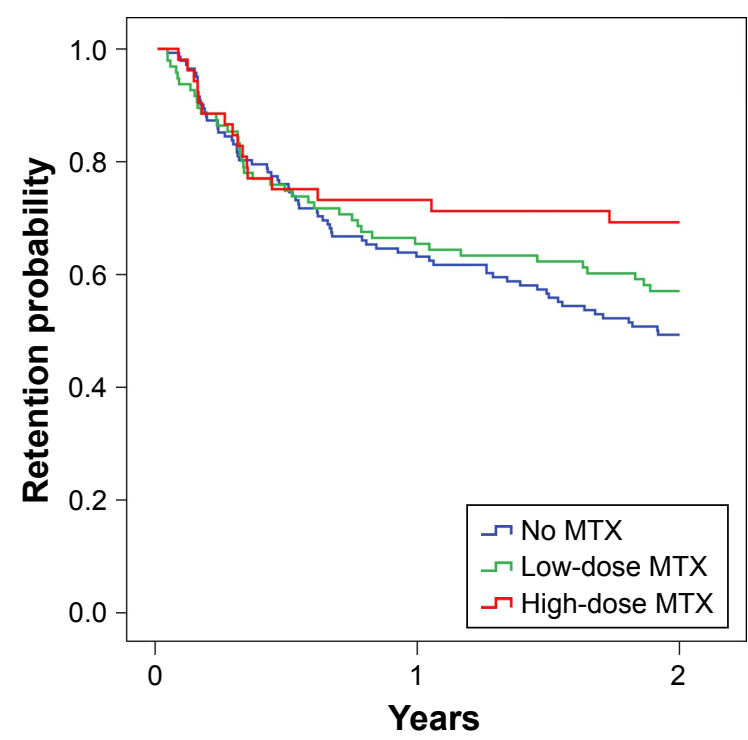

Number of patients at risk

$\begin{array}{llll}\text { No MTX } & 141 & 87 & 67 \\ \text { Low-dose MTX } & 90 & 58 & 51 \\ \text { High-dose MTX } & 48 & 33 & 30\end{array}$

Figure 3 Two-year drug survival of TNFi treatment according to maintenance of baseline concomitant MTX regimen.

Abbreviation: MTX, methotrexate. 
A

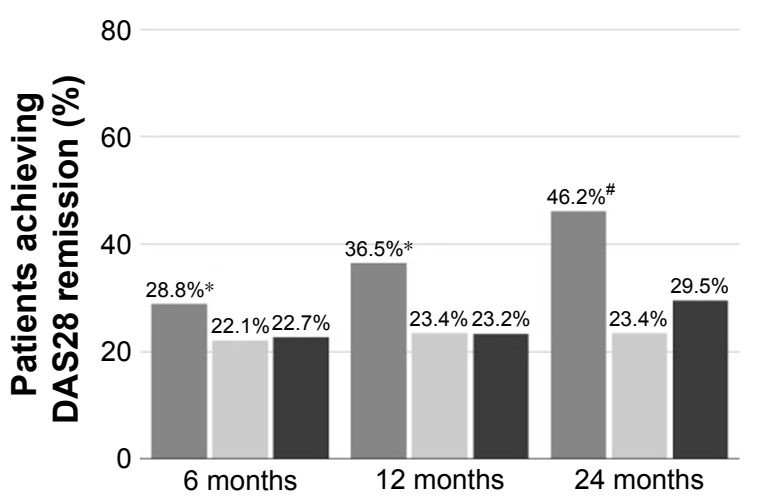

B

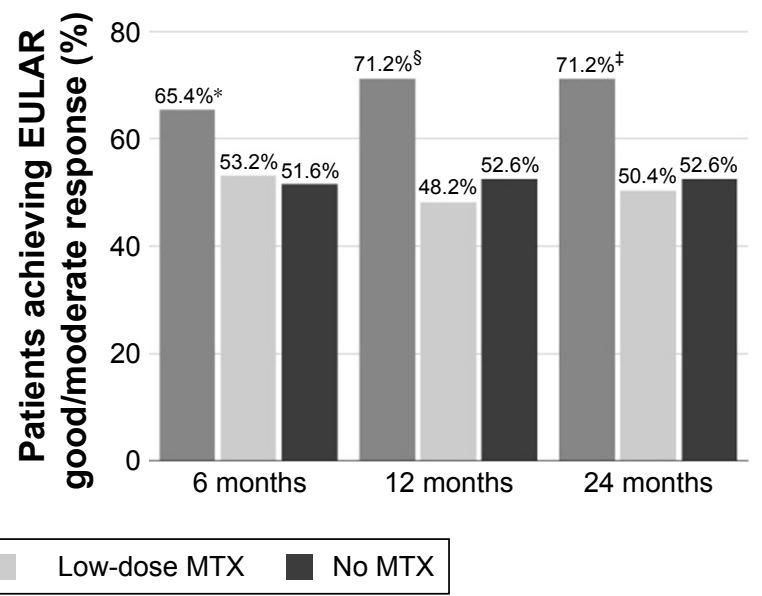

Figure 4 The impact of maintenance of baseline concomitant MTX regimen on (A) DAS28 remission and (B) European League Against Rheumatism good/moderate clinical response.

Notes: ${ }^{*} p=$ not significant, ${ }^{*} p=0.009,{ }^{\S} p=0.017,{ }^{\ddagger} p=0.031$.

Abbreviations: DAS28, Disease Activity Score 28; MTX, methotrexate.

The mean change from baseline in DAS28 score was significantly greater in high-dose MTX-treated patients than in low-dose and no MTX groups at 6 months (1.99 \pm 1.51 vs $1.43 \pm 1.38$ and $1.32 \pm 1.39$, respectively; $p=0.029$ ), 12 months ( $2.25 \pm 1.67$ vs $1.41 \pm 1.40$ and $1.29 \pm 1.41$, respectively; $p=0.002)$, and 24 months $(2.39 \pm 1.73$ vs $1.52 \pm 1.55$ and $1.26 \pm 1.57$, respectively; $p=0.001$ ). The proportion of patients achieving DAS28 remission was higher in the stable high-dose MTX group than in both the low-dose and no MTX groups, with a trend to a progressively increasing difference over time, which was not significant at 6 months ( $25 \%$ vs $21.1 \%$ and $22.7 \%$, respectively; $p=0.614$ ), increased at 12 months ( $35.4 \%$ vs $22.2 \%$ and $23.2 \%$, respectively; $p=0.142$ ), and increased even further, becoming significant, at 24 months $(46.2 \%$, vs $23.4 \%$ and $29.5 \%$, respectively; $p=0.009$ ). Similarly, the proportion of patients achieving good/moderate EULAR response was higher in the stable high-dose MTX group than in both the low-dose and no MTX groups at 6 months $(65.4 \%$ vs $53.2 \%$ and $51.6 \%$, respectively; $p=0.235), 12$ months ( $71.2 \%$ vs $48.2 \%$ and $52.6 \%$, respectively; $p=0.017)$, and 24 months $(71.2 \%$ vs $50.4 \%$ and $52.6 \%$, respectively; $p=0.031$ ) (Figure 4 ). On the other hand, in the group of subjects undergoing MTX dose de-escalation/ discontinuation because of adverse events or poor compliance, we observed worsening in the 2-year DAS28 score in $66.7 \%$ of patients (median increase 0.37 [IQR: $0.25-0.83$ ]).

\section{Discussion}

This retrospective analysis of real-life data has demonstrated the importance of the concomitant MTX regimen in the achievement of favorable clinical outcomes in RA patients treated with a first-line TNFi, such as ADA or ETA. Our findings show that baseline combination with MTX is a strong predictor of EULAR response and suggest that MTX high-dose maintenance over time is associated with a higher probability of achieving and maintaining a clinical remission. To the best of our knowledge, this is one of the first papers analyzing the pattern of MTX regimen modification over time and the effect of MTX dose changes on clinical response to TNFis.

Indeed, our analysis has also confirmed that the proportion of patients receiving ADA or ETA without MTX in a real-life setting is surprisingly high $(>40 \%)$ in consideration of the clear indication provided by international recommendations that all bDMARDs should be used in combination with MTX. ${ }^{15,16}$ This result is consistent with what has been reported by similar observational studies based on national registries, such as the British BSRBR registry $(32 \%),{ }^{11}$ the Swedish ARTIS registry (30\%), ${ }^{18}$ the German RABBIT registry $(34 \%),{ }^{19}$ the Swiss SCQM registry $(39 \%),{ }^{30}$ the Norwegian NOR-DMARD $(33 \%),{ }^{31}$ the US CORRONA registry $(30 \%),{ }^{32}$ the Austrian BIOREG registry $(40 \%)^{33}$ and the Italian GISEA registry $(33 \%) .{ }^{20}$ The reasons for this suboptimal use of concomitant MTX in TNFi-treated patients lie in the overall poor tolerability reported by MTX users, who frequently experience gastrointestinal (nausea, vomiting, and abdominal pain) or neurological (headache, light headedness, vertigo, dizziness, lethargy, and fatigue) adverse events, leading to drug dose decrease or discontinuation ${ }^{26}$ and causing low drug adherence. ${ }^{27}$ In a very long observational study (follow-up 13.3 years, mean doses of MTX between 12.4 and $14.6 \mathrm{mg} / \mathrm{wk}$ ), gastrointestinal adverse events were the 
most common side effects $(52 \%-65 \%)$, while neurological events were observed in $21 \%-38 \%$ of patients and elevations of liver enzymes (above the upper limit of normal) occurred especially during the first 4 years of treatment (69\%-88\%) and then decreased (25\% then $15 \%$ after 79 months). ${ }^{34}$ More recently, Salliot and van der Heijde showed a prevalence of raised liver enzymes (more than twice the upper limit of normal) close to $13 \%$, with only $3.7 \%$ of patients stopping MTX permanently owing to liver toxicity. ${ }^{35}$ Similar to what reported in a retrospective analysis conducted on a British database, ${ }^{36}$ in our cohort as well, gastrointestinal and neurological intolerance was the most frequent reason for failure to continue MTX therapy, accounting for $60 \%$ of TNFi monotherapy prescriptions, whereas previous hepatotoxicity and low drug adherence were each responsible for $20 \%$.

As expected, we found TNFi with no MTX to be more common in older patients with a longer mean disease duration. These findings are not surprising considering that, although evidence from clinical trials suggests that synthetic and biologic DMARDs have good efficacy and are well tolerated in elderly patients, such individuals are often undertreated because of safety concerns. ${ }^{37}$ Moreover, in our cohort, female sex was associated with high frequency of monotherapy/low-dose concomitant MTX, as a result of poorer MTX tolerability in women, which has already been reported by other similar analyses. ${ }^{38,39}$

The optimal MTX dose to be associated with TNFis is still unclear. According to the 2009 international recommendations on the use of MTX in rheumatic disorders, in newly diagnosed RA patients oral MTX should be started at $10-15 \mathrm{mg} / \mathrm{wk}$, with rapid escalation by $5 \mathrm{mg}$ every $2-4$ weeks up to $20-30 \mathrm{mg} / \mathrm{wk}$, depending on clinical response and tolerability. ${ }^{40}$ However, the CONCERTO trial showed that in ADA-treated RA, 6-month efficacy of 10 and $20 \mathrm{mg} / \mathrm{wk}$ oral MTX appeared equivalent, suggesting that for patients initiating ADA combination therapy, the optimal starting dose may be lower than previously assumed. ${ }^{23}$ Accordingly, in our cohort, the baseline median MTX dose was $10 \mathrm{mg} / \mathrm{wk}$. This finding may partially reflect the prescription behavior of MTX at suboptimal doses reported by a recent survey (the MARI study) conducted in 60 Italian rheumatology units, which reported that only $15.2 \%$ of patients are treated with $\geq 15 \mathrm{mg} /$ wk MTX $^{41}$ However, MTX had been mainly prescribed by parenteral route in both our cohort $(76.2 \% \mathrm{vs}$ $23.8 \%$, respectively) and the MARI study $(77.7 \%$ vs $22.3 \%$, respectively), a route that potentially improves overall treatment efficacy as a consequence of increased bioavailability. ${ }^{42}$ Nevertheless, in our analysis, the highest MTX dose was associated with the greatest probability to achieve a 2-year EULAR clinical response, demonstrating that even MTX dosage is crucial over a longer follow-up period compared with what was reported in the CONCERTO trial. ${ }^{23}$

Beyond the initial prescription of TNFis as monotherapy or in combination with low-dose MTX, poor tolerability also affects concomitant MTX maintenance over time. A recently published survey conducted in RA patients treated with self-administered bDMARDs showed that only $45 \%$ of the respondents were using MTX cotherapy despite a monotherapy prescription only in $27 \%$ of all patients. ${ }^{43}$ In our cohort, almost one-third of the 189 patients receiving MTX experienced MTX dose tapering or withdrawal because of intolerance or adverse events, with persistence of the baseline MTX regimen in $79.9 \%$ of patients at 1 year and $70.2 \%$ at 2 years. Longer disease duration predicted this maintenance over time of MTX dosage as a potential effect of the selection of patients probably treated with MTX for a longer period and thus less prone to develop MTX intolerance.

Most previously published papers evaluating TNFi monotherapy efficacy in a real-life setting were conducted by classifying mono- or combination therapy according to baseline concomitant MTX treatment alone and assuming MTX regimen to be stable over time. Conversely, a retrospective analysis from the Swiss Clinical Quality Management registry for RA described $13 \%$ of initial combination therapy patients discontinuing concomitant MTX over time. ${ }^{12}$ Similarly, we quantified the proportion of patients undergoing MTX dose decrease/discontinuation over a 2-year follow-up period, but in addition, we analyzed the impact of this dose change on TNFi effectiveness over time, demonstrating the importance of MTX maintenance beyond MTX initial dose. In fact, we found a clear trend, albeit not statistically significant, toward an increase in the 2-year retention rate in patients maintaining high-dose MTX compared with subjects undergoing MTX dose reduction/discontinuation. Moreover, mean change from baseline of DAS28 and the proportion of patients achieving remission or good/moderate EULAR response were all significantly higher in patients who maintained the initial MTX regimen than in patients who did not. On the other hand, MTX dose reduction or discontinuation because of intolerance was associated with an increase in DAS28 values in almost two-thirds of patients, thus resulting in suboptimal disease control.

The main limitation of the present study is its observational retrospective design without randomization. Consequently, patients with different baseline characteristics could have been channeled to a specific MTX regimen, producing 
selection bias and potentially affecting our comparative analysis. However, we observed that the MTX subgroups were well balanced, with no statistically significant differences in baseline mean DAS28, mean HAQ score, and RF positivity. Moreover, as is usual in long-term analyses, the number of patients at risk tended to progressively decrease over time, becoming relatively small at the end of the evaluated follow-up period, partially influencing the impact of results. On the other hand, the most important strengths are the fact that the study design focused for the first time on concomitant MTX evaluation over time in a cohort of TNFi-treated patients and the very frequent collection of data on MTX regimen (every 2 months), which was crucial for a more comprehensive analysis of MTX dose changes over time.

\section{Conclusion}

We showed that in a real-life setting, about one-third of RA patients treated with a TNFi experienced dose reduction/ discontinuation of concomitant MTX because of intolerance/ adverse events over a 2-year follow-up period. This change in MTX dosage, as well as initial low-dose or no MTX, was associated with poorer 2-year clinical response, suggesting the importance of prescribing right from the beginning highdose concomitant MTX in combination with TNF blockers and maintaining it over time. The high proportion of patients receiving TNFis alone along with the high rate of MTX dose reduction or discontinuation observed in our cohort make the efficacy of TNFi without MTX a potential unmet need in the management of RA. In this scenario, interleukin- 6 blockers, ${ }^{44}$ and more recently small molecules (such as Janus Kinase inhibitors), ${ }^{45,46}$ have been proven to be highly effective even when used as monotherapy; so, in the last update of EULAR recommendations, these mechanisms of action are indicated as the preferential alternative option for treating patients with contraindications or intolerance to MTX. ${ }^{16}$

Future analyses in larger populations and over a longer follow-up period are warranted to confirm our results.

\section{Disclosure}

Editorial and medical writing support was provided by CDM and TBWA and was funded by Pfizer. Favalli EG and Becciolini A received an honorarium from Pfizer in connection with the development of this manuscript. Biggioggero M, Crotti C, Raimondo MG, and Marchesoni A did not receive any honorarium from Pfizer in connection with the development of this manuscript. Bertoldi I is a Pfizer employee. The authors report no other conflicts of interest in this work.

\section{References}

1. Smolen JS, Breedveld FC, Burmester GR, et al. Treating rheumatoid arthritis to target: 2014 update of the recommendations of an international task force. Ann Rheum Dis. 2016;75(1):3-15.

2. Favalli EG, Biggioggero M, Meroni PL. Methotrexate for the treatment of rheumatoid arthritis in the biologic era: still an "anchor" drug? Autoimmun Rev. 2014;13(11):1102-1108.

3. Keystone EC, Kavanaugh A, Sharp JT, et al. Radiographic, clinical, and functional outcomes of treatment with adalimumab (a human anti-tumor necrosis factor monoclonal antibody) in patients with active rheumatoid arthritis receiving concomitant methotrexate therapy: a randomized, placebo-controlled, 52-week trial. Arthritis Rheum. 2004;50(5): 1400-1411.

4. Breedveld FC, Weisman MH, Kavanaugh A, et al. The PREMIER study: a multicenter, randomized, double-blind clinical trial of combination therapy with adalimumab plus methotrexate versus methotrexate alone or adalimumab alone in patients with early, aggressive rheumatoid arthritis who had not had previous methotrexate treatment. Arthritis Rheum. 2005;54(1):26-37.

5. Lipsky PE, van der Heijde DM, Clair EWS, et al. Infliximab and methotrexate in the treatment of rheumatoid arthritis. Anti-Tumor Necrosis Factor Trial in Rheumatoid Arthritis with Concomitant Therapy Study Group. N Engl J Med. 2000;343(22):1594-1602.

6. Klareskog L, van der Heijde DM, De Jager JP, et al. Therapeutic effect of the combination of etanercept and methotrexate compared with each treatment alone in patients with rheumatoid arthritis: double-blind randomised controlled trial. Lancet. 2004;363(9410):675-681.

7. Keystone EC, van der Heijde DM, Mason D Jr, et al. Certolizumab pegol plus methotrexate is significantly more effective than placebo plus methotrexate in active rheumatoid arthritis: Findings of a fifty-two-week, phase III, multicenter, randomized, double-blind, placebo-controlled, parallel-group study. Arthritis Rheum. 2008;58(11):3319-3329.

8. Keystone EC, Genovese MC, Klareskog L, et al. Golimumab, a human antibody to tumour necrosis factor given by monthly subcutaneous injections, in active rheumatoid arthritis despite methotrexate therapy: the GO-FORWARD Study. Ann Rheum Dis. 2009;68:789-796.

9. Favalli EG, Pregnolato F, Biggioggero M, et al. Twelve-year retention rate of first-line tumor necrosis factor inhibitors in rheumatoid arthritis: reallife data from a local registry. Arthritis Care Res. 2016;68(4):432-439.

10. Becciolini A, Biggioggero M, Favalli EG. The role of methotrexate as combination therapy with etanercept in rheumatoid arthritis: retrospective analysis of a local registry. J Int Med Res. 2016;44(Suppl 1):113-118.

11. Soliman MM, Ashcroft DM, Watson KD, et al; British Society for Rheumatology Biologics Register. Impact of concomitant use of DMARDs on the persistence with anti-TNF therapies in patients with rheumatoid arthritis: results from the British Society for Rheumatology Biologics Register. Ann Rheum Dis. 2011;70(4):583-589.

12. Gabay C, Riek M, Scherer A, Finckh A; SCQM collaborating physicians. Effectiveness of biologic DMARDs in monotherapy versus in combination with synthetic DMARDs in rheumatoid arthritis: data from the Swiss Clinical Quality Management Registry. Rheumatology (Oxford). 2015;54(9):1664-1672.

13. Kremer JM, Genant HK, Moreland LW, et al. Effects of abatacept in patients with methotrexate-resistant active rheumatoid arthritis: a randomized trial. Ann Intern Med. 2006;144(12):865-876.

14. Cohen SB, Emery P, Greenwald MW, et al. Rituximab for rheumatoid arthritis refractory to anti-tumor necrosis factor therapy: results of a multicenter, randomized, double-blind, placebo-controlled, phase III trial evaluating primary efficacy and safety at twenty-four weeks. Arthritis Rheum. 2006;54(9):2793-2806.

15. Singh JA, Saag KG, Bridges SL Jr, et al. 2015 American College of Rheumatology Guideline for the treatment of rheumatoid arthritis. Arthritis Rheumatol. 2016;68(1):1-26.

16. Smolen JS, Landewé R, Bijlsma J, et al. EULAR recommendations for the management of rheumatoid arthritis with synthetic and biological disease-modifying antirheumatic drugs: 2016 update. Ann Rheum Dis. 2017;76(6):960-977. 
17. Mariette X, Gottenberg JE, Ravaud P, Combe B. Registries in rheumatoid arthritis and autoimmune diseases: data from the French registries. Rheumatology (Oxford). 2011;50(1):222-229.

18. Askling J, Fored CM, Brandt L, et al. Time-dependent increase in risk of hospitalisation with infection among Swedish RA patients treated with TNF antagonists. Ann Rheum Dis. 2007;66(10):1339-1344.

19. Listing J, Strangfeld A, Rau R, et al. Clinical and functional remission: even though biologics are superior to conventional DMARDs overall success rates remain low - results from RABBIT, the German biologics register. Arthritis Res Ther. 2006;8(3):R66.

20. Atzeni F, Sarzi-Puttini P, Botsios C, et al. Long-term anti-TNF therapy and the risk of serious infections in a cohort of patients with rheumatoid arthritis: comparison of adalimumab, etanercept and infliximab in the GISEA registry. Autoimmun Rev. 2012;12(2):225-229.

21. Favalli EG, Desiati F, Atzeni F, et al. Serious infections during anti$\mathrm{TNF} \alpha$ treatment in rheumatoid arthritis patients. Autoimmun Rev. 2009;8(3):266-273.

22. Heiberg MS, Kaufmann C, Rødevand E, et al. The comparative effectiveness of anti-TNF therapy and methotrexate in patients with psoriatic arthritis: 6 month results from a longitudinal, observational, multicentre study. Ann Rheum Dis. 2007;66(8):1038-1042.

23. Burmester GR, Kivitz AJ, Kupper H, et al. Efficacy and safety of ascending methotrexate dose in combination with adalimumab: the randomised CONCERTO trial. Ann Rheum Dis. 2015;74(6):1037-1044.

24. Gallo G, Brock F, Kerkmann U, Kola B, Huizinga TWJ. Efficacy of etanercept in combination with methotrexate in moderate-tosevere rheumatoid arthritis is not dependent on methotrexate dosage. RMD Open. 2016;2(1):e000186.

25. Manders SHM, Kievit W, Adang E, et al. Effectiveness of TNF inhibitor treatment with various methotrexate doses in patients with rheumatoid arthritis: results from clinical practice. Ann Rheum Dis. 2015; 74(3):e24.

26. Romão VC, Lima A, Bernardes M, Canhão H, Fonseca JE. Three decades of low-dose methotrexate in rheumatoid arthritis: can we predict toxicity? Immunol Res. 2014;60(2-3):289-310.

27. Manara M, Bianchi G, Bruschi E, et al. Adherence to current recommendations on the use of methotrexate in rheumatoid arthritis in Italy: results from the MARI study. Clin Exp Rheumatol. 2016;34(3):473-479.

28. van den Bemt BJF, Zwikker HE, van den Ende CHM. Medication adherence in patients with rheumatoid arthritis: a critical appraisal of the existing literature. Expert Rev Clin Immunol. 2012;8(4):337-351.

29. Arnett FC, Edworthy SM, Bloch DA, et al. The American Rheumatism Association 1987 revised criteria for the classification of rheumatoid arthritis. Arthritis Rheum. 1988;31(3):315-324.

30. Du Pan SM, Dehler S, Ciurea A, et al. Comparison of drug retention rates and causes of drug discontinuation between anti-tumor necrosis factor agents in rheumatoid arthritis. Arthritis Rheum. 2009;61(5):560-568.

31. Heiberg MS, Koldingsnes W, Mikkelsen K, et al. The comparative one-year performance of anti-tumor necrosis factor $\alpha$ drugs in patients with rheumatoid arthritis, psoriatic arthritis, and ankylosing spondylitis: Results from a longitudinal, observational, multicenter study. Arthritis Rheum. 2008;59(2):234-240.

32. Lee SJ, Chang H, Yazici Y, Greenberg JD, Kremer JM, Kavanaugh A. Utilization trends of tumor necrosis factor inhibitors among patients with rheumatoid arthritis in a United States observational cohort study. J Rheumatol. 2009;36(8):1611-1617.
33. Rintelen B, Zwerina J, Herold M, et al. Validity of data collected in BIOREG, the Austrian registry for biological treatment in rheumatology: current practice of bDMARD therapy in rheumatoid arthritis in Austria. BMC Musculoskelet Disord. 2016;17(1):358.

34. Kremer JM. Safety, efficacy, and mortality in a long-term cohort of patients with rheumatoid arthritis taking methotrexate: followup after a mean of 13.3 years. Arthritis Rheum. 1997;40(5):984-985.

35. Salliot C, van der Heijde DM. Long-term safety of methotrexate monotherapy in patients with rheumatoid arthritis: a systematic literature research. Ann Rheum Dis. 2009;68(7):1100-1104.

36. Nikiphorou E, Negoescu A, Fitzpatrick JD, et al. Indispensable or intolerable? Methotrexate in patients with rheumatoid and psoriatic arthritis: a retrospective review of discontinuation rates from a large UK cohort. Clin Rheumatol. 2014;33(5):609-614.

37. Boots AMH, Maier AB, Stinissen P, Masson P, Lories RJ, De Keyser F. The influence of ageing on the development and management of rheumatoid arthritis. Nat Rev Rheumatol. 2013;9(10):604-613.

38. Hider SL, Silman AJ, Thomson W, Lunt M, Bunn D, Symmons DPM. Can clinical factors at presentation be used to predict outcome of treatment with methotrexate in patients with early inflammatory polyarthritis? Ann Rheum Dis. 2009;68(1):57-62.

39. McKendry RJ, Dale P. Adverse effects of low dose methotrexate therapy in rheumatoid arthritis. $J$ Rheumatol. 1993;20(11):1850-1856.

40. Visser K, Katchamart W, Loza E, et al. Multinational evidence-based recommendations for the use of methotrexate in rheumatic disorders with a focus on rheumatoid arthritis: integrating systematic literature research and expert opinion of a broad international panel of rheumatologists in the 3E Initiative. Ann Rheum Dis. 2009;68(7):1086-1093.

41. Idolazzi L, Adami S, Capozza R, et al. Suboptimal methotrexate use in rheumatoid arthritis patients in Italy: the MARI study. Clin Exp Rheumatol. 2015;33(6):895-899.

42. Schiff MH, Jaffe JS, Freundlich B. Head-to-head, randomised, crossover study of oral versus subcutaneous methotrexate in patients with rheumatoid arthritis: drug-exposure limitations of oral methotrexate at doses $\geq 15 \mathrm{mg}$ may be overcome with subcutaneous administration. Ann Rheum Dis. 2014;73(8):1549-1551.

43. Aaltonen KJ, Turunen JH, Sokka T, Puolakka K, Valleala H. A survey on the medication adherence to methotrexate among rheumatoid arthritis patients treated with self-administered biologic drugs. Clin Exp Rheumatol. 2016;34(4):694-697.

44. Dougados M, Kissel K, Conaghan PG, et al. Clinical, radiographic and immunogenic effects after 1 year of tocilizumab-based treatment strategies in rheumatoid arthritis: the ACT-RAY study. Ann Rheum Dis. 2014;73(5):803-809.

45. Lee EB, Fleischmann R, Hall S, et al. Tofacitinib versus methotrexate in rheumatoid arthritis. N Engl J Med. 2014;370(25):2377-2386.

46. Fleischmann R, Schiff M, van der Heijde DM, et al. Baricitinib, methotrexate, or combination in patients with rheumatoid arthritis and no or limited prior disease-modifying antirheumatic drug treatment. Arthritis Rheumatol. 2017;69(3):506-517.

\section{Publish your work in this journal}

Drug Design, Development and Therapy is an international, peerreviewed open-access journal that spans the spectrum of drug design and development through to clinical applications. Clinical outcomes, patient safety, and programs for the development and effective, safe, and sustained use of medicines are the features of the journal, which

\section{Dovepress}

has also been accepted for indexing on PubMed Central. The manuscript management system is completely online and includes a very quick and fair peer-review system, which is all easy to use. Visit http://www.dovepress.com/testimonials.php to read real quotes from published authors. 